\title{
FIGURA EM MINHA LÍNGUA: DA TRADUÇÃO EM VERSO \\ DO VERSO DRAMÁTICO DE WILLIAM SHAKESPEARE, UM PROJETO PARA RICARDO III
}

\author{
Marcos Barbosa de Albuquerque
}

\section{Já foi mulher em tal humor flertada?}

É possível que nenhum outro personagem de Shakespeare tenha jamais se defrontado com uma missão de sucesso tão improvável quanto a que se coloca ao Duque de Gloster já na segunda cena do primeiro ato de Ricardo III: Em meio a sua escalada insana e sangrenta pela coroa da Inglaterra, Ricardo de Gloster (futuro rei), motivado por um certo "secreto intento", apenas alcançável pelo intermédio de um matrimônio, sabe que todo seu futuro depende de seu êxito, nesse exato instante, de “flertar" com Lady Ana e de "flechar" seu coração.

Ana e Gloster estão agora frente-a-frente, mas as circunstâncias que se colocam como obstáculo ao sucesso da empreitada do duque são gigantescas: Recentemente enviuvada de seu amado esposo, o jovem herdeiro Eduardo, Lady Ana teve seu luto há pouco redobrado pelo assassinato de Henrique, seu sogro, rei destronado e finado soberano da casa Lancaster. As mortes de Henrique e de Eduardo marcavam o fim absoluto de uma dinastia, agora que os York inimigos tomavam definitivamente o trono, selando o desfecho da Guerra das Duas Rosas. Quando o York Gloster se depara com Ana, ela está mesmo a guiar um séqüito armado que conduz o esquife de Henrique para o sepultamento no solo santo de Chertsey.

O simples fato de que Lady Ana se expõe publicamente dessa forma, num momento de tanta instabilidade política, já é prova suficiente de sua profunda devoção filial ao finado Rei Henrique e à casa Lancaster e de sua têmpera de caráter. Mas ainda mais significativo para a compreensão da gravidade da situação dramática que se desenha nesse encontro é o dado de que Lady Ana conhece bem a identidade do "abscesso podre e deformado" que executou ambos seu esposo e seu sogro: Trata-se do Duque de Gloster em pessoa. E tanto que, confirmando antigas crenças, a simples 
presença de Gloster diante do cadáver de Henrique faz com que as chagas do morto "destravem as bocas" e "vertam sangue novo", denunciando a chegada do assassino.

“Já foi mulher em tal humor flertada? Já foi mulher em tal humor flechada?"

Nunca, até então. Nunca, desde então. E o fato de que Shakespeare, diante de tamanho imbróglio, logra tão plenamente convencer seus leitores da verossimilhança do sucesso do Duque de Gloster em suprimir o ódio e despertar o afeto em Lady Ana nessa seqüência de quarenta e poucas réplicas é mais uma prova da genialidade do bardo.

As ferramentas empregadas na tessitura dramática de uma cena tão complexa são, naturalmente, de ordens diversas: Em parte somos preparados para aceitar o sucesso de Gloster devido ao caráter fortemente metateatral do texto, que desde sua abertura é apresentado como uma encenação a ser conduzida por uma espécie de mestre-decerimônias da fábula (o próprio Gloster). Acaba então por parecer natural ao espectador que a substância de que é feito este narrador-personagem seja de uma natureza mais intensa que a de qualquer outro personagem da trama e que a ele, Gloster, seja dado lograr o que seria ilícito aos demais. Esse caráter metateatral do texto, de tão patente, chega a ser o eixo central de toda uma escola de encenações da peça, como demonstra um levantamento crítico de Gillian Day (2002) acerca das encenações de Ricardo III em Stratford-upon-Avon (cidade natal de Shakespeare, Inglaterra), entre 1945 e 2001.

Também colabora nessa construção dramatúrgica a fina manipulação da retórica na construção do diálogo dramático, traço marcado do conjunto da obra de Shakespeare, aqui levado a um extremo de requinte e empregado na instauração de um cosmos ético particular, no qual "existem apenas o ódio, o desejo e a violência; existe apenas o Grande Mecanismo [da história] que transforma o carrasco em vítima e a vítima, em carrasco", lavrando, na avaliação de Jan Kott, "uma das maiores cenas que Shakespeare já escreveu, uma das maiores que já foram escritas" (2003:59 e 56).

Mas há ainda um outro importantíssimo plano no qual se constrói o jogo que nos convencerá do valor e da plenitude da vitória do Duque de Gloster sobre Lady Ana: Trata-se do arcabouço formal da linguagem da peça, lá onde Shakespeare estrutura e desenha, em versos, o diálogo que conferirá ao embate entre Gloster e Ana a instauração de um sentimento de verdade que se estabelece como arranjo melódico, como canção.

\section{A dramática na dança dos versos}

Ricardo III, Ato I, Cena 2: Lady Ana pede ao cortejo fúnebre do Rei Henrique que pare para descanso, enquanto ela "presta o obséquio de um lamento à queda temporã de 
um bom Lancaster." Nessa seqüência de trinta e dois versos, Shakespeare marcará a base formal de verso dramático sobre a qual será construído o drama: o pentâmetro jâmbico.

Verso decassílabo formado em sucessão de cinco jambos (pares de sílabas que se constroem em padrão breve-longa), o pentâmetro jâmbico é marca paradigmática do verso dramático empregado por Shakespeare e pelos demais dramaturgos do teatro isabelino em suas comédias e tragédias. É fácil enxergar o funcionamento deste modelo quando se observa, na declamação de um dos mais célebres versos de Shakespeare ("To be or not to be, that is the question"), que as sílabas nas quais recaem as ênfases tonais são as de posição par ("be", "not”, "be”, "is", "ques”), ficando as sílabas menos enfatizadas ("To", “or", "to", "that", "the”) nas posições ímpares. A última sílaba, “tion”, por ser posterior à última tônica, não entrará na contagem de sílabas poéticas (de forma similar ao que acontece nos sistemas francês, português e provençal de contagem de sílabas poéticas).

A entrada de Gloster na cena ainda não alterará esse padrão métrico. Aliás, a manutenção do modelo será por ora de extrema importância, uma vez que o debate entre Gloster e Ana sucederá, com freqüência, pela troca de pentâmetros jâmbicos que funcionam como espelhos negativos. E já ano primeiro momento em que Gloster se dirigir diretamente a Ana, tratando-a por "anjo doce" ("Sweet Saint, for Charity, be not so curst." ${ }^{\text {) }}$, ela responderá com um verso que opõe, numa afronta de terrível simetria, a imagem do "anjo doce" à de um "diabo podre" ("Foule Diuell, For Gods sake hence, and trouble vs not,").

Esse jogo de espelhos partidos crescerá durante a cena e, já no movimento de réplicas seguinte, o paralelismo romperá a estrutura interna do verso e galgará um nível mais alto, em que as trocas se darão através de falas com número praticamente exato de versos (2-2, 1-1, 4-3, 2-2). É dizer que Gloster e Ana se debatem em golpes calculados, para os quais ação e reação são de fato grandezas simétricas e opostas, como no modelo físico newtoniano das forças. Nessa esgrima, eles não desperdiçam energia nem fogem

\footnotetext{
${ }^{1}$ Os versos de Ricardo III serão sempre citados a partir da versão folio, de 1623, disponível para consulta no sítio da Internet Shakespeare Editions. http://ise.uvic.ca/Annex/Texts/R3/F1/Scene/ (último acesso em 17 de junho de 2006). Acrescento aqui a ressalva de que as publicações modernas de Ricardo III são manipulações editoriais desta publicação e ainda das cinco impressões conhecidas da versão quarto, de 1597. A escolha deste texto fonte, portanto, não visa garantir uma assinatura rígida e originária de William Shakespeare (tarefa de qualquer forma impossível), mas sim levar em conta traços de oralidade presentes nos registros das edições medievais, os quais são importantes para a compreensão do caráter melódico da elocução. Esses traços, entretanto, costumam ser apagados pelas revisões ortográficas das edições modernas.
} 
ao seu dispêndio. E Shakespeare marca, assim, recorrendo ao auxílio de um jogo métrico, o sinal de uma proximidade anímica que ajudará o autor a desenhar a vindoura vitória de Gloster sobre Ana.

O primeiro golpe certeiro de Gloster neste embate vem em forma um pedido, um pedido que desestabilizará as estratégias de sua oponente: "Say that I slew them not". Pedir a Ana que declare o duque inocente das mortes de Henrique e Eduardo tem, por si, valor de assombro. Mas é preciso reparar que, nesse instante, Shakespeare dá que Gloster rogue essa afronta com um verso de seis sílabas, rompendo o delicado jogo rítmico que construiu até agora.

Da importância do decassílabo (pentâmetro jâmbico) na recepção das peças de Shakespeare pelas platéias do medievo inglês, dirá o diretor inglês Richard Eyre (apud Kermode, 2001:4; tradução minha):

\begin{abstract}
A vida das peças está na linguagem, não em paralelo a ela, ou subordinada a ela. Pensamentos e sentimentos são liberados no momento do discurso. Uma platéia isabelina terá respondido ao pulso, aos ritmos, às formas, sons e, acima de tudo, de acordo com a consistência dos versos brancos decassílabos de cinco pés. Eram uma platéia que ouvia.
\end{abstract}

Assim, diante do pedido hexassílabo de Gloster, não é só Ana que se desestabiliza, mas toda a platéia que subitamente é arrebatada para fora de um debate que se construíra até então na consistência de oitenta e oito versos decassílabos.

Ana cai na armadilha de Gloster, respondendo impensadamente com outro verso de seis sílabas (“Then say they were not slaine:”), mas ainda é cedo para que ela ceda de vez ao duque e é assim que a vemos rapidamente trazer o diálogo de volta ao terreno já conhecido dos decassílabos (“But dead they are, and diuellish slaue by thee.”).

Ocorre que, nesse ponto, Gloster já terá encontrado, na manipulação da linguagem, um caminho para a alma de Ana. O diálogo já estará contaminado e Shakespeare já terá plantado as sementes de ruptura que desestabilizarão a platéia que "ouve", convencendo seus espectadores da justeza do sucesso de Gloster também através da variação de ritmos no diálogo, da construção de uma sinistra canção de flerte.

O embate entre Gloster e Ana segue, Shakespeare leva adiante os jogos de simetria e sinaliza, aqui e ali, que a teia dos decassílabos (e de toda a razão) está em vias de romper. Faz isso, por exemplo, dividindo um só verso em duas vozes (o que marca, na linguagem dramática, a fricção entre os personagens), ou recorrendo a breves partículas de fala que funcionam quase como um relampejo de fuga para a prosa. 
Em meio a esse conflito de idéias, paixões e ritmos, Ana ainda encontrará ensejo para cuspir no rosto de Gloster e ele - numa prova de extrema ousadia, digna de um dos maiores vilões shakespeareanos — ainda a desafiará a executá-lo, pondo-lhe um punhal nas mãos e oferecendo o peito nu ao golpe.

Em sua análise da cena, Jan Kott (2003:58) defende que Ana é vencida quando Gloster consegue convencê-la de que as regras do mundo em que vivem são ditadas apenas pelo desejo e que todo o mal que o duque tenha impingido ao mundo foi fruto de sua paixão por ela (“But 'twas thy Beauty that prouoked me.”). Em qualquer caso, digo que toda essa retórica só é de fato aflorada dramaturgicamente na peça a partir de um recurso de ordem formal na construção dos versos. Digo que o momento em que se percebe finalmente que Ana cedeu irreversivelmente a Gloster se dá quando, desafiada a cobrar o suicídio de Gloster, ela hesita e, abandonando suas convicções, abandona também o arcabouço dos decassílabos: "I would I knew thy heart."

Essa é a deixa pela qual Gloster esperou até agora. A partir dessa réplica de Ana, o metro que o separa dela já não é mais o dez sílabas, mas o de seis, o mesmo que ele experimentara antes para desconcertá-la, o mesmo que ela antes evitara mas que, agora, é instaurado justamente por ela. Shakespeare marca esse momento construindo uma série de réplicas em esticometria (trocas de falas que se dão em sucessões de versos únicos por parte de cada personagem). Onze versos hexassílabos e, ao fim deles, Ana aceita usar o anel que lhe é oferecido por Gloster.

Aí, nesse arranjo em que o arcabouço formal do verso do dramático é indissociável do drama da cena, é que se colocam aos tradutores de Ricardo III as questões que esboço abordar neste artigo. Questões que só podem ser notadas quando os versos dramáticos do texto-fonte são finalmente traduzidos como... versos dramáticos.

\section{Entre verso e prosa}

Essa última ressalva acerca da especificidade da tradução de versos como versos pode parecer vazia, mas é muito significativa uma vez que corre, em língua portuguesa, toda uma linhagem de traduções de Shakespeare que substituem os versos dramáticos do texto-fonte por prosa, em tradução. Trata-se de uma escola com origem nobre, que aponta para o primeiro conjunto sistematizado de publicações de traduções de peças de Shakespeare para o português, assinadas por um rei de Portugal, Dom Luís I, que deu a lume versões de Hamlet (1877), O Mercador de Veneza (1879), Ricardo III (1880) e Otelo, o Mouro de Veneza (1885) (Homem, 2001:20). É possivelmente em acordo com 
essa tradição que a prosa é o registro no qual vêm sendo escritas, desde 2001, as traduções da série portuguesa "Shakespeare para o século XXI", projeto deflagrado pelo Departamento de Estudos Anglo Americanos da Faculdade de Letras da Universidade do Porto, em associação com a editora Campo das Letras, da Cidade do Porto, visando à publicação da totalidade da obra dramática de Shakespeare em traduções assinadas, introduzidas e anotadas por acadêmicos especializados.

Aliás, a opção pela tradução versificada do verso dramático de Shakespeare encontra bem poucos adeptos em Portugal. Até o momento, em minha pesquisa, localizei apenas dois títulos com essa natureza: Sonho d'uma noite de São João, assinada pelo Visconde António Feliciano de Castilho (1874), e Julio César, em tradução de Luís Cardim (1925), ao qual ainda não tive acesso direto.

No Brasil, os tradutores de Shakespeare que optam pela estratégia formal da prosa também encontram largo espaço editorial e contam com importantes nomes das letras nacionais em seus quadros, caso de Millôr Fernandes, de Geraldo Carneiro e de Paulo Mendes Campos. Mas corre aqui, com força, uma segunda vertente de traduções que se aparta da tradição portuguesa e que responde com versos aos versos de Shakespeare. Essa linhagem de traduções em verso foi provavelmente inaugurada em nosso país pelo poeta simbolista Onestaldo de Pennafort, que em 1940 publicou, em versos, Romeu e Julieta, e se estende desde então no extenso trabalho de tradutores como Artur de Sales, Péricles Eugênio da Silva Ramos, Anna Amélia Queiroz Carneiro de Mendonça, Geir Campos, Jorge Wanderley, Bárbara Heliodora, Aíla de Oliveira Gomes e José Roberto O'Shea.

A partir de um levantamento de traduções brasileiras da obra dramática de Shakespeare organizado pela professora Marcia A. P. Martins (PUC-Rio) (inédito), é possível aproximar que cerca de sessenta por cento dos quase cento e cinqüenta títulos listados inserem-se justamente no universo das traduções em verso, o que basta para conferir uma marca nacional distinta da verificada na prática da portuguesa de traduções da obra dramática de Shakespeare.

\section{Ricardo III em traduções brasileiras}

De Ricardo III, especificamente, conheço quatro traduções brasileiras publicadas: a de Carlos Alberto Nunes (primeira metade dos anos cinqüenta), a de F. C. Cunha Medeiros e Oscar Mendes (final dos anos sessenta), a de Anna Amélia Queiroz Carneiro 
de Mendonça (concluída em 1968, mas com publicação tardia, em 1993) ${ }^{2}$ e a tradução/adaptação de Jô Soares (2006). Destas, são traduções em verso apenas a de Nunes e a de Mendonça.

Poeta, dramaturgo, tradutor e médico legista, o maranhense Carlos Alberto Nunes realizou no início da década de cinqüenta uma empreitada até agora jamais reproduzida no Brasil por um tradutor trabalhando individualmente: a tradução completa da obra dramática de Shakespeare. Nunes estabeleceu como meta manter em suas traduções a consonância com a prosa ou com o verso, de acordo com o verificável no texto-fonte, e tomou como formato paradigmático para seu verso em tradução o modelo "decassílabo heróico" (verso de dez sílabas com acentos na sexta e na décima).

Bastante particular em sua escolha de palavras e vasto no emprego de inversões e de malabarismos sintáticos, Nunes viria a ser objeto de recorrentes acusações de arcaísmo por parte da crítica (Gomes, 1961:70; O’Shea,1997). Mas nada ofusca o brilho deste diligente tradutor, que também legaria ao Brasil a primeira tradução dos Diálogos de Platão realizada desde o grego (e publicada em catorze volumes pela Universidade Federal do Pará, na década de setenta), traduções em verso da Ilíada e da Odisséia de Homero e da Eneida de Virgílio e ainda traduções de várias de peças de Goethe e de Hebbel.

Anna Amélia Queiroz Carneiro de Mendonça, por sua vez, é uma das grandes poetisas brasileiras da primeira metade do século XX. Seu nome está intimamente associado ao seu trabalho junto à Casa do Estudante do Brasil (Rio de Janeiro, anos trinta), e também ao Teatro do Estudante do Brasil, grêmio teatral amador capitaneado por Paschoal Carlos Magno e responsável pela primeira encenação brasileira de Shakespeare: Romeu e Julieta, com direção de Itália Fausta, em 1938, na tradução portuguesa de Domingos Ramos (Vargas, 2005:35).

Anna Amélia ingressa na tradução da obra dramática de Shakespeare em 1968, por insistência de sua filha, Bárbara Heliodora (então professora de história do teatro e hoje uma das mais profícuas tradutoras e comentadoras da obra de Shakespeare no Brasil), que lhe encomendou traduções de Hamlet e de Ricardo III para uso em sala de aula. Poetisa que trabalhara largamente com o metro decassílabo em sonetos de sua própria lavra, Anna Amélia não parece ter encontrado dificuldade em traduzir, neste metro, o verso dramático de Shakespeare, como atesta um depoimento de Bárbara

\footnotetext{
${ }^{2}$ A data de conclusão da tradução de Ricardo III por Anna Amélia Queiroz Carneiro de Mendonça foi registrada a partir de entrevista com Bárbara Heliodora. Rio de Janeiro, 19/10/2005.
} 
Heliodora: "Ela traduzia com uma facilidade inacreditável. Eu me lembro que um dia eu cheguei em casa e ela disse assim: 'Você vai ficar aborrecida.' Eu disse: 'Por que?' 'Porque tinha uma cena em prosa, eu não reparei e fiz toda em verso!' (ver nota 3 ).

A tradução de Anna Amélia para Ricardo III é um trabalho de extremo cuidado e de notável qualidade, e se revela ainda hoje um marco no exercício da tradução brasileira do verso dramático de Shakespeare.

\section{Um projeto}

É principalmente a partir destas duas traduções (a de Nunes e a de Mendonça), que desenvolvo atualmente, junto ao Programa de Pós-Graduação em Artes Cênicas da Universidade Federal da Bahia, uma tese de doutoramento que envolve a feitura de mais uma tradução em verso de Ricardo III.

Aqui, o objetivo é conduzir a tradução de modo que o caráter dramático da forma do verso seja observado em sua especificidade de elemento do jogo cênico - como fica demonstrado nesse estudo de uma cena específica de Ricardo III. O trabalho de tradução, que deverá contar ainda com uma fase de experimentação em oficina de leitura com alunos e professores da Escola de Teatro da UFBA, ainda não está concluído, mas já estão traçadas as diretrizes gerais que servirão de condições de contorno:

\section{Variação prosa-verso}

Há no conjunto da obra dramática de Shakespeare uma recorrente variação entre trechos em prosa e trechos em verso e, se o verso dá a tônica desse conjunto, a prosa chega mesmo a preponderar em obras como As alegres comadres de Windsor e Noite de Reis. São muitas as teorias sobre o significado da prosa e do verso dentro do ambiente dramático das peças de Shakespeare (Kermode, 2001), mas penso que mais importante que estabelecer uma função ou poética dramatúrgica inerente à prosa ou ao verso é perceber que a variação entre um e outro estilo é usada, por Shakespeare, como ferramenta de condução da ação dramática.

O exemplo mais célebre dessa variação, em Shakespeare, dá-se provavelmente na segunda cena do quarto ato de Júlio César, quando na ágora discursam aos plebeus dois nobres romanos: Brutus e Marco Antônio. O primeiro defende, em prosa, o valor do assassinato de Júlio César; o segundo desmonta, em verso, o discurso do primeiro. E 
não é surpresa que Marco Antônio ouça vazar da multidão uma voz que diz: "Ninguém mais nobre, em Roma, do que Antônio!".

Em Ricardo III a prosa surge quase que em caráter de exceção, mas servirá para marcar, por exemplo, a distância entre o discurso (e o estado de espírito) dos assassinos contratados por Gloster para matar seu irmão, o Duque de Clarence, e o discurso do nobre que será apunhalado: Aqueles falam em prosa, este fala em verso (Ato I, Cena 4).

Esse tipo de variação, que obviamente se revela menos cristalina em uma tradução feita exclusivamente em prosa, ganha assim relevo e significância numa tradução ocupada com a observância da variação prosa-verso, como a que se desenvolve no âmbito desse projeto.

\section{Metrificação}

Além da manutenção das variações prosa-verso, proponho-me ainda a trabalhar com um jogo de metrificação similar ao que ocorre no texto-fonte, dando ensejo à instauração dos jogos formais desenvolvidos por Shakespeare, como no caso do câmbio entre metros de seis e dez sílabas que marca a aproximação e a repulsa entre o Duque de Gloster e Lady Ana.

Aliás, cabe dizer que entre as traduções em verso da obra dramática de Shakespeare para o português há várias que se estruturam com versos de metros mais longos que os do texto-fonte. Talvez a maior motivação para essa estratégia seja a intrínseca dificuldade de se traduzir, dentro de um número limitado de sílabas, a mesma carga de informação semântica encontrada em um verso em inglês. Isso porque a farta recorrência de monossílabos e dissílabos em língua inglesa acaba por permitir a alocação, no verso, de uma média de palavras bastante mais elevada que a que se faz possível quando se trabalha em língua portuguesa.

São exemplos de tradutores que trabalham com metros mais longos em suas traduções de Shakespeare nomes como Oscar Bastian Filho (Julio César, 1946), Artur de Sales (Macbeth, 1952) e Péricles Eugênio da Silva Ramos (Hamlet, 1955). Uma particularidade com relação ao trabalho de Sales é que o autor recorre em seu trabalho ao verso alexandrino (doze sílabas poéticas, com tônica de cesura na sexta, sucedendose em dísticos rimados), modelo paradigmático da tragédia neoclássica francesa: 
Diz seu papel e sai. E ninguém mais o nota,

É um conto narrado aí por um idiota,

Cheio de sons, de fúria e não dizendo nada. (p. 122)

\section{Ritmo}

Um ponto que começa a apartar o trabalho em desenvolvimento neste projeto de tradução dos realizados anteriormente por Nunes e Mendonça diz respeito ao intento expresso de estabelecimento de um ritmo jâmbico na construção dos versos traduzidos. Como já descrito aqui, o pentâmetro jâmbico não esgota sua particularidade no metro de dez sílabas poéticas, mas pressupõe ainda que essas sílabas sucedam-se em padrão breve-longa.

O modelo decassílabo heróico adotado por Nunes, por exemplo, caminha na direção do pentâmetro jâmbico ao firmar a ocorrência de tônicas na sexta e na décima posições silábicas, mas deixa em aberto a distribuição das demais sílabas fortes, abarcando versos que, ao serem declamados, eventualmente não guardam muita semelhança rítmica com o pentâmentro jâmbico.

A busca pela construção de um ritmo jâmbico numa tradução em espanhol (e penso que a idéia possa ser estendida, assim, ao português) foi descrita pela tradutora argentina Cristina Piña (1999:20) como algo menos sensato, e cabe notar ainda que Segismundo Spina (2003) de fato não registra nenhum padrão decassilábico semelhante ao pentâmetro jâmbico em seu Manual de versificação românica medieval; mas o mesmo Spina cita, de Arturo Marasso, essa idéia luminosa: "desde o momento que uma língua adquire vida própria, todos os versos possíveis estão implícitos nela” (p. 29; tradução minha).

De fato, ocorrem nas traduções de Nunes e de Mendonça — mas com muito maior freqüência na de Mendonça - versos que podem ser declamados como pentâmetros jâmbicos. É o caso, por exemplo (na tradução de Mendonça), desta fala de Gloster aos guardas do corpo do Rei Henrique, diante do séqüito guiado por Lady Ana: "Vilões, baixai o corpo, ou por São Paulo / Farei cadáver quem desobedeça!” (Shakespeare, 1993:25).

$\mathrm{Na}$ tradução que desenvolvo, a busca deste padrão rítmico é apenas reforçada em relação ao que ocorre nas traduções anteriores de Nunes e de Mendonça e trabalho no sentido de trazer à tona, com maior freqüência, este modelo rítmico específico. 


\section{Interlinearidade}

Uma condição de contorno também estabelecida para este projeto de tradução diz respeito ao caráter interlinear da tradução, o que implica na ocorrência, entre versos traduzidos e versos-fonte, de uma correspondência biunívoca. Essa limitação visa, entre outras coisas, a preservar o caráter específico do tempo necessário à declamação de cada fala no texto de Shakespeare.

A recorrente dificuldade já apontada aqui de se conseguir traduzir para o português, em espaço limitado de sílabas, a mesma carga semântica de um verso em inglês, é por vezes driblada pelos tradutores com o desdobramento dos versos em tradução, o que eventualmente gera traduções que são mais extensas que o texto-fonte. Assim é que no solilóquio de entrada de Lady Ana, Shakespeare oferece 32 versos, Mendonça 33 e Nunes 38.

A diferença, aqui, pode parecer irrisória, mas será importantíssima, por exemplo, na escrita dramatúrgica das esticometrias, quando o que é dito importa, para o drama, tanto quanto o tempo que demanda para ser dito. A respeito deste aspecto revelador da fala dramatúrgica, escreve Eric Bentley (1981:83) em seu A experiência viva do teatro:

Quanto tempo uma pessoa fala pode ser tão importante quanto o que ela diz. O primeiro esboço redigido pelo dramaturgo de uma cena de grupo poderia muito bem conter um apontamento como "aqui $A$ fala durante cinco segundos". (...) Quebrar esse ritmo seria mais funesto que omitir essa ou aquela declaração.

\section{Idade das palavras}

A acusação de arcaísmo, que ainda pesa sobre o trabalho de tradução de Carlos Alberto Nunes, deriva em parte do recurso do autor a uma escolha de palavras absolutamente fora de uso, e não é preciso procurar muito para encontrar em sua tradução de Ricardo III palavras como "imigo", "féretro" ou "amolgadas". Mas já à época do lançamento da obra dramática completa de Shakespeare em tradução sua, Nunes comentou assim seu estilo: "No que diz respeito ao vocabulário, não poupei esforços para fazer justiça à opulência do original, assim quanto à variedade como na escolha dos têrmos (sic)."

O oposto da estratégia de Nunes seria talvez recorrer, nas traduções de Shakespeare, a um vocabulário de vocação mais contemporânea, corriqueira e familiar, mas penso que isso também não contribuiria artisticamente para a instauração de um universo vocabular vasto e múltiplo como o que Shakespeare nos oferece em suas 
peças. Acerca da questão, o tradutor alemão Erich Fried (in Elsom:1989:41; tradução minha) se posiciona da seguinte forma: "Eu nunca utilizei, que eu soubesse, palavras que brotaram em alemão após a revolução industrial, porque não penso que alguém deva tentar forçosamente fazer Shakespeare contemporâneo."

Alinhado a Fried e a Nunes, permito-me, em tradução, o recurso a um vocabulário menos comum e corriqueiro na tradução de Ricardo III, evitando, entretanto, os vocábulos que dificultem excessivamente a compreensão de uma literatura que, quando em encenação, não permitirá uma segunda "leitura" aos seus ouvintes. Para estabelecer um limite de idade dos vocábulos, atenho-me a palavras que tenham "brotado" em português antes do advento do século XIX, trabalho facilitado através da interface de pesquisa de datação de vocábulos que integra o CD ROM Dicionário eletrônico Houaiss da língua portuguesa (2002), que serve como dicionário de referência para esse trabalho de tradução.

\section{Uso das segundas pessoas}

Em suas revisões para as traduções de Hamlet e de Ricardo III, de Anna Amélia Queiroz Carneiro de Mendonça, Bárbara Heliodora intervém, por exemplo, com a supressão do recurso à segunda pessoa do plural (à exceção dos casos em que o recurso indica variações patentes de hierarquia, como nas falas dirigidas ao Rei Cláudio, em Hamlet). Essas intervenções têm a função de garantir, outra vez, uma mais clara compreensão do texto por parte de seus leitores e espectadores, considerando-se o caráter anacrônico do emprego das muitas vezes obscuras conjugações em "vós" (ver nota 3$)$.

O recurso é legítimo e, de fato, parece predominar entre os tradutores brasileiros do verso dramático de Shakespeare, mas se dá a custo do esmaecimento de uma outra faceta dramatúrgica dos requintes da linguagem do bardo: o emprego, como ação dramática, da variação you/thou:

Usa-se you para se dirigir a um mais nobre ou a um igual em hierarquia de quem se guarda distância respeitosa. Usa-se thou para os íntimos ou para os menores em realeza. Por vezes, o emprego de um ou de outro termo é bastante revelador do estado de espírito de uma personagem com relação ao seu interlocutor.

Na cena de Ricardo III que abordo aqui, por exemplo, o embate entre Gloster e Ana começa com o duque tratando-a com a deferência do you ("Lady, you know no Rules of Charity,") e ela atiçando-o com o rebaixamento do thou ("Villaine, thou 
know'st nor law of God or Man,"). Ocorre que, à medida que a cena progride, Gloster sorrateiramente mudará de estratégia e passará a tratar Ana por thou ("Curse not thy selfe faire Creature, thou art both.”). E quando a cena chega ao ápice marcado pela esticometria em hexassílabos, Ana oscilará e, eventualmente, cederá em deferência diante do Duque, tratando-o por you ("Well, well, put up your Sword.”).

Quando os dois se despedem (e meio que se dão conta, finalmente, de que estão sendo observados), a formalidade volta a imperar e you será o tratamento empregado por ambos.

Este projeto de tradução emprega, similarmente ao que faz Nunes, uma equivalência "vós"/you e "tu"/thou. O custo, por certo, é o risco de obscurecer o significado de algumas passagens em que as conjugações assumem formas menos corriqueiras; o ganho é a possibilidade de instauração de um jogo de poder verbal que é significativo na construção da ação dramática das peças de Shakespeare.

\section{Shakespeare, o oceano}

Desenho aqui, dessa forma, esse projeto de tradução (ainda não concluído, ainda passível de mudança e de transformação), na esperança de que o compartilhar dessas estratégias lancem luz, talvez, sobre a leitura e a análise de outras traduções. Mas não se pode dizer muito sobre um projeto que ainda se esboça e menos ainda se pode concluir a seu respeito.

Aliás, o concluso e o definitivo não parecem ser categorias facilmente atribuíveis a aproximações do trabalho de Shakespeare... Abro uma edição do Hamlet em tradução de Péricles Eugênio da Silva Ramos e leio esta epígrafe atribuída a Victor Hugo (Shakespeare, 1976:III):

Dois exilados - pai e filho - estão numa ilha deserta cumprindo longa pena. Numa manhã, sentados em frente à casa, o filho pergunta: "Que pensas deste exílio?" "Será longo..." responde o pai. "E como ocupá-lo?" continua o jovem. O velho, sereno, diz apenas: "Olharei o oceano e tu?". Faz-se um longo silêncio antes da resposta do jovem: "Eu traduzirei Shakespeare". Shakespeare: o oceano.

Shakespeare: o oceano. 


\section{Referências bibliográficas}

BENTLEY, Eric (1981 [1965]) A experiência viva do teatro. Trad. de Álvaro Cabral. Rio de Janeiro: Zahar.

ELSOM, John (org.) (1989) Is Shakespeare still our contemporary? London: Routledge.

DAY, Gillian (2003) King Richard III. Zrinski: The Arden Shakespeare; The Shakespeare Birthplace Trust.

GOMES, Eugênio (1961) William Shakespeare no Brasil. Rio de Janeiro: Ministério da Educação e Cultura.

HOMEM, Rui Carvalho (2201) “Of Negroes, Jews and kings”. The Translator: Studies in Intercultural Communication 7 (1), 19-42.

HOUAISSS, Antônio et al. (eds.) (2002). Dicionário eletrônico Houaiss da língua portuguesa. CD ROM versão 1.0.5.a. Editora Objetiva.

KERMODE, Frank (2001) Shakespeare's language. London: Penguin.

KOTT, Jan (2003 [1961]) Shakespeare nosso contemporâneo. Trad. de Paulo Neves. São Paulo: Cosac \& Naify.

MARTINS, Marcia A. P. "Traduções do teatro de Shakespeare no Brasil”. Inédito.

O’SHEA, José Roberto (1997) “Antony and Cleopatra em tradução". In: SHAKESPEARE, William. Antônio e Cleópatra. Trad. de José Roberto O’Shea. São Paulo: Mandarim.

PIÑA, Cristina (1999) "Prólogo". SHAKESPEARE, William. Ricardo III. Trad. de Cristina Piña. Buenos Aires: Losada.

SHAKESPEARE, William (1954 [1611 e 1594]) A tempestade e A comédia dos erros. Trad. de Carlos Alberto Nunes. São Paulo: Melhoramentos.

(s/d; 1950-59? [1592-3?]) A tragédia do rei Ricardo III. Trad. de Carlos Alberto Nunes. São Paulo: Melhoramentos.

(1976 [1602-4?]) Hamlet. Trad. de Péricles Eugênio da Silva Ramos [1955]. 3 ed. São Paulo: Abril Cultural.

(1952 [1606? e 1608]) Macbeth e Rei Lear. Trad. de Artur de Sales e J. Costa Neves. Rio de Janeiro: Jackson Inc. Coleção Clássicos Jackson, vol. X.

(1969) Obra completa. vol. 1. Trad. de F. Carlos de Almeida Cunha e Oscar Mendes. Rio de Janeiro: Aguilar. 
(2006 [1592-3?]) Ricardo III. Trad. e adaptação de Jô Soares. São Paulo: Imprensa Oficial do Estado de São Paulo.

(1993 [1592-3? e 1600]) Ricardo III e Henrique V. Trad. de Ana [sic] Amélia Carneiro de Mendonça e Barbara Heliodora. Rio de Janeiro: Nova Fronteira. (1946 [1597]) Romeu e Julieta. Trad. de Onestaldo de Pennafort [1940]. 2 ed. Rio de Janeiro: Livraria Globo.

(1950 [1598]) Sonho d'uma noite de São João. Trad. de António Feliciano de Castilho [1874]. Lisboa: Lello e Irmão.

SPINA, Segismundo (2003 [1971]) Manual de versificação românica medieval. Cotia: Ateliê Editorial.

VARGAS, Maria Thereza (2005) Sônia Oiticica: uma atriz rodrigueana?. São Paulo: Imprensa Oficial do Estado de São Paulo; Fundação Padre Anchieta. 